UDK: 72.012:711.4

DOI: https://doi.org/10.24867/03FA23Kurtanovic

\title{
ARHITEKTONSKA STUDIJA IZGRADNJE SAVREMENOG TRGOVINSKOG CENTRA IZNAD NAJLON PIJACE U NOVOM SADU
}

\section{ARCHITECTURAL STUDY OF CONSTRUCTION OF A MODERN TRADE CENTER OVER NAJLON MARKET IN NOVI SAD}

Enes Kurtanović, Dragana Konstantinović, Slobodan Jović, Fakultet tehničkih nauka, Novi Sad

\section{Oblast - ARHITEKTURA}

Kratak sadržaj - Rad se bavi istraživanjem strategija $i$ modela zajedničkog funkcionisanja tradicionalnih $i$ savremenih prostora za prodaju u urbanim sredinama. Kao poseban model razmatra se postupak nadgradnje tradicionalnih otvorenih prostora gradskih pijaca, zbog formiranja ekonomski isplativijih $i$ funkcionalno korisnijih parcela. Ovaj postupak unapređuje procese socijalizacije, nudeći korisnicima tradicionalne pijace da imaju bezbedan prostor, uz očivanje njegovog identiteta.

Ključne reči: Arhitektonsko projektovanje, šoping centar, pijace, najlon pijaca

\begin{abstract}
The paper deals with the research of strategies and models of the common functioning of traditional and modern facilities for sale in urban areas. As a special model, the superstructure over traditional open city markets is being considered, due to the formation of economically more profitable and functionally more useful plots. This approach promotes the processes of socialization, providing users of the traditional market to have a safe place, while preserving the existing identity.
\end{abstract}

Keywords: Architectural and urbanism design, shopping center, markets, flee markets

\section{UVOD}

$\mathrm{Na}$ našem tržištu tržni centri predstavljaju relativno nov koncept poslovanja. Oduvek je postojala težnja ljudi da se na jednom mestu omogući spajanje ponude i tražnje. Bilo da je reč o antičkim agorama, bazarima, otvorenim tržnim centrima ili organizovanim zatvorenim prostorima sa mnoštvom prodavnica između kojih je jedna ,ulica“.

Ta potreba za spajanjem ponude i tražnje na jednom mestu uslovila je pojavu ogromnih trgovinskih kompleksa prepunih sadržaja za zabavu i razonodu.

U pitanju je koncept koji omogućava posetiocima da na jednom mestu pronađu sve što je potrebno jednoj ulici uz mnoštvo veoma atraktivnih zabavnih sadržaja.

\footnotetext{
NAPOMENA:

Ovaj rad proistekao je iz master rada čiji mentor je bila dr Dragana Konstantinović, docent, a komentor Slobodan Jović.
}

Tržni centri postaju „novi centri grada“, mesto gde je „najbolja zabava u gradu“. Za bolje poslovanje ovakvog objekta neophodno je uspostaviti harmoniju svih elemenata koji su uključeni u poslovanje.

Predmet rada je razmatranje odnosa tradicionalne pijace i savremenog tržnog centra, od prvih pijaca i bazara do savremenih tržnih centara. Rad se bavi analizom uspešnog rešavanja tržnih centara današnjice, koji su doveli do stvaranja visokovrednih objekata ovog tipa; ovo se pre svega odnosi na sociološki uticaj u tržnim centrima. Rad se takođe bavi istraživanjem dodatnih sadržaja koji karakterišu zabavni javni prostor u tržnim centrima.

Cilj rada je analiza aspekata mesta za trgovinu kroz odnose sa javnim prostorom, kao i sagledavanje novih identitetskih, kulturnih, ekonomskih, estetskih, socijalnih i fizičkih odlika javnog prostora koji karakterišu inovativni elementi u planiranju savremenih tržnih centara, upravo ove odlike prostor u tržnom centru čine mnogo kvalitetnijim.

Uspešnost poslovanja tržnih centara generalno zavisi od toga koliko je ostvaren koncept savremene funkcionalno organizacione koncepcije prostora, što je i osnovna hipoteza ovog rada. Rad se takođe bavi trenutnim stanjem i analizom primera nadgradnje tržnica iz tržišno ekonomski razvijenih zemalja koje su daleko odmakle u praktičnom rešavanju ove problematike.

Metodološki gledano, rad se zasniva na uočavanju postojećih modernih tendencija $u$ cilju stvaranja najkvalitetnijih rešenja za projektovanje tržnih centara. Ta rešenja uključuju transformaciju tržnog centra kao mesta na kojem se samo nabavljaju namirnice u mesta koja predstavljaju savremeni prostor u kojem je moguće druženje i socijalizacija.

\section{SOCIOLOŠKI ZNAČAJ TRŽNIH CENTARA}

Trgovina je našla svoje mesto u javnom urbanom prostoru sa ostalim socijalnim aktivnostima ljudi, oduvek je bila deo urbane slike gradova. Međutim, postavlja se pitanje kakav uticaj tržni centri imaju danas u društvu, gde se snabdevanje namirnicama za zadovoljenje dnevnih potreba ljudi poistovetilo sa odlaskom u šoping centrima i tu se pronalazi svaki vid zadovoljstva.

Multifunkcionalnost tržnih centara učinila je da oni postanu mali gradovi sposobni da zadovolje želje kupaca - posetilaca. To su postigli uključivanjem aktivnosti, predmeta, slika koje se ne prodaju ali privlače populaciju. 
Ovo potvrđuje činjenica da je jedna od glavnih karakteristika savremenih tržnih centara da su oni izuzetno funkcionalno prilagodljivi podneblju kojem pripadaju, tržnim centrima koji su na snazi u drugim faktorima.

Primetno je da se povećava socijalni pritisak na projektante tržnih centara kako bi oni bili energetski održiviji, ekološki prihvatljiviji i društveno korisniji. Što znači da će u budućnosti biti potrebno projektovati tržne centre tako da oni budu manji energetski potrošači, odnosno da više koriste alternativne oblike energije. Ako je objekat energetski efikasniji više odgovara i vlasnicima lokala, jer sa manjom potrošnjom energije izdvajaju i manje sredstava za iznajmljivanje lokala.

Takođe, jako je važno prilagoditi i podići svest o projektovanju tržnica koje će u budućnosti predstavljati novi oblik kondenzatora, objekat koji će svojom multifunkcionalnošću predstavljati novo mesto kulturnih, ekonomskih, društvenih i drugih aktivnosti važnih za zajednicu u kojoj se nalazi.

\section{SAVREMENI TRŽNI CENTRI - PROBLEMI PROJEKTOVANJA}

Problematika projektovanja modernih prodajnih mesta izuzetno je složena. Dizajniranje ovakvih objekata predstavlja složen proces, jer problemi koji postoje evoluiraju, povećava se broj prodajnih mesta koja imaju sasvim nove karakteristike, koja zadovoljavaju posebne zahteve i bave se posebnom vrstom usluga.

Današnja tendencija u projektovanju prodajnih mesta je njihovo integrisanje u gradske centre gde postaju dodatak prednostima centralnog urbanog jezgra i sastavni delovi okruženja.

Novi dinamični tipovi prodajnog mesta uslovljavaju promenjivost temeljnih principa na kojima se zasnivaju moderni tržni centri, kao i iznalaženje novih projektantskih rešenja koja imaju za cilj prilagodljivost zahtevima prodavaca i kupaca.

Da bi tržni centar bio idealan mora imati raznolikost ponude, koja oslikava dinamičnu prirodu tržnog centra. Međutim, pored toga postoji težnja ka stvaranju još unikatnijih, još interesantnijih prostora u tržnim centrima, kao i izgleda samog centra.

Zato se pri projektovanju ovih objekata moraju uzeti u obzir različiti aspekti o kojima se mora posebno voditi računa, jer bitno utiču na krajnji rezultat i ocenu uspešnosti projekta.

Tri najbitnije kategorije o kojima se mora voditi računa pri projektovanju idealnog tržnog centra jesu:

- Socijalni aspekt;

- Kvalitet arhitektonsko - urbanističkog rešenja;

- Ekonomska dobit za prodavnice u tržnom centru [1].

Socijalni aspekt uzima u obzir želje potrošača, tendencije u potrošnji, njihovu bezbednost i sigurnost. Želje potrošača su promenjive zavisno od doba godine, doba dana, polne, starosne i druge strukture stanovništva.

Glavni cilj je stvoriti doživljaj koji će doprineti tome da tržni centar postane turistička destinacija, gde bi posetioci osim robe i usluga „kupovali“ i iskustvo. Osim toga, bitno je obezbediti dovoljno ugostiteljskog, zabavnog sadržaja, koji je skoro iste važnosti kao i trgovačka aktivnost, jer je za kupce veoma bitno da se osećaju kao gosti.

Posetioci uvek očekuju nešto novo, tako da se moraju osluškivati njihove želje kako bi ugođaj bio na najvećem nivou. U objektu se mora stvoriti prijatan ambijent koji će potrošače - posetioce dovesti opet. Veoma je bitno da tržni centar donosi ekonomsku dobit gradu, vlasniku objekta ili zakupcu lokala. Zato ponudu treba prilagoditi željama potrošača, odnosno prilagoditi strukturu robe i usluga navikama potrošača, dobu dana ili godine, jer od toga zavisi isplativost investicije.

Za idealan tržni centar bitno je stvaranje kombinacije otvorenog i zatvorenog prostora sa naglašenom dinamikom izloga različitog dizajna, stvaranje prostora koji nema jasno definisane granice, nema jasno definisane pragove koji bi ga odvajali od ostatka grada, gde se garantuje bezbednost i sigurnost i nudi se mnoštvo trgovačkog, ugostiteljskog i zabavnog sadržaja.

Za posetioce je jako bitno da je tržni centar zanimljiv, lepog i modernog dizajna; da je uočljiv, zanimljivog izgleda - boje, oblika i osvetljenja. Ne sme delovati tmurno, jeftino i dosadno.

Oko idealnog tržnog centra trebalo bi postojati zelenilo, drveće, manje travnate površine. Idealan tržni centar je izuzetno pregledan, dobro osvetljen. I boje zidova bi trebalo da budu vesele i vedre (narandzasta, žuta i zelena $\mathrm{i}$ td.). Poželjne su i oznake gde se šta nalazi, kao i plan tržnog centra na svakom spratu. Za ugodnu atmosferu je bitna i muzika koja ne sme biti preglasna i prenapadna. Ventilacija i prijatna temperatura su veoma važne za kupce.

Da bi trgovački centar bio idealan bitne su i pristupačne cene, širok asortiman, pristupačnost i dostupnost. Pristupačnost je veoma bitna jer je u poslednjih nekoliko decenija došlo do rasta broja starih i nemoćnih osoba. Pored toga potrebe i zahtevi različitih članova stanovništva (deca, trudnice, odrasli, starije osobe i osobe sa invaliditetom) variraju.

Iz tog razloga, danas postoji povećana svest o univerzalnom dizajnu među dizajnerima kako da zadovolje potrebe različitih korisnika u mnogim zemljama širom sveta.

Tržni centri su posebno važni za aktivnosti u slobodno vreme u velikim urbanim centrima, koji bi trebalo da osiguraju da su svi ljudi podjednako dobrodošli i da svi posetioci mogu da učestvuju.

Postoji pet principa koji se trebaju poštovati prilikom projektovanja i uređenja tržnog centra (objekti za javno korišćenje) [2]:

1. Funkcionalni sistem - rampe, liftovi, pokretne stepenice, hodnici i koridori,

2. Ulaz i izlaz - da su lako uočljivi

3. Kretanje kroz tržni centar, čvorovi, ivice, zone, grafički simboli kao što su piktogrami

\section{Prostor za odmor i čekanje}

5. Javni sadržaj: javni telefoni, toaleti i jedinice za sedenje Osim toga, bitno je da je ugodan, veseo ambijent, uredan i lepo uređen prostor, kvalitetna ponuda, ljubazno osoblje. 


\section{ODNOS JAVNOG GRADSKOG PROSTORA I ŠOPING CENTRA}

Javnim gradskim prostorima se nazivaju „svi prostori između kuća u gradu i ostalih izgrađenih mesta" [3] Prostor koji je namenjen i isključivo služi funkcijama javne namene, omogućava socijalnu komunikaciju, pristupačan je i otvoren svima predstavlja javni prostor. Oni predstavljaju mesta stalnog kretanja ljudi i neku vrstu „spontanog pozorišta“, mesta na kojima se „razmenjuju reči i znakovi“ [4]. Valter Bendžamin (Walter Benjamin) ističe kako se zbog razvoja tržišta i trgovine razvijaju pasaži, novi oblici javnih prostora koji danas nemaju samo ulogu protaka ljudi već i funkciju razmene robe i sticanja kapitala.

Nekadašnja uloga trga se polako gubi, njima se danas suprostavljaju objekti namenjeni trgovini, koji sve više preuzimaju njihovu ulogu. Trg koji je predstavljao centar društveno-kulturnog života zajednice polako nestaje, jer njihovu ulogu danas preuzimaju u velikoj meri savremeni šoping centri. Trg je predstavljao mesto okupljanja, socijalizacije, trgovine, ali i mesto tradicije, kolektivne memeorije i odraz svojih građana.

Međutim, prelaskom funkcija namenjenih za javni otvoreni prostor u prostore tržnih centara, trg gubi taj osnovni značaj i poprima ulogu predvorja objekta javne namene. Danas se na trgu većinom realizuju aktivnosti privremenog i improvizovanog karaktera, dok su ostale funkcije zanemarene.

Tržne centre karakteriše veći stepen komfora, bezbednosti, koncentracije aktivnosti i raznovrsnosti zabavnih sadržaja, oni postaju bolja, prihvatljivija i atraktivnija mesta za socijalizaciju. Nestajanje javnog prostora i pojava pseudo-javnih prostora sa ograničenim pristupom događa se uporedo sa agresijom komercijalne kulture i pojavom kulturnog spektakla. „Razlika između javnog i pseudo-javnog prostora je $\mathrm{u}$ tome da ovaj drugi predstavlja privatiziranu javnu sferu. On se, doduše, čini kao javna sfera, ali po obliku svojine i funkcionisanja i nema baš mnogo potencijala javnosti“ [6].

Majk Dejvis (Mike Davis) objašnjavajući odnos javnog i pseudo-javnog prostora kaže da su ovi drugi, projektovani prostori koji su planski osmišljeni da zavaraju korisnika smislenim pregradama koje odvraćaju od određenih prostora, ali koji u velikoj meri u čovekovoj svesti ne predstavljaju barijere, tako gradeći svest potpuno javnog prostora, ipak svi oblici pristupa i ponašanja u ovakvim tipovima prostora su čvrsto ograničeni pomoću jakih sistema sigurnosti.

Dalje, objašnavajući razlike, Dejvis kaže: „Projektanti šoping molova i pseudo-javnih prostora napadaju publiku, tako što je homogenizuju. Oni predstavljaju arhitektonske i semiotičke barijere da bi filtrirali „nepoželjne“.

Zatvaraju masu koja ostaje unutra, usmeravajući njihovo cirkulisanje sa bihejviorističkom žestinom. Ona namamljuje posetioce vizuelnim stimulansima svih vrsta, pa čak i primenom raznih mirisa“" [7].

Zaključujemo da se sve više teži izgradnji i formiranju prostora bez barijera (pseudo prostora), tj. prostora koji su podređeni korisniku i koji funkcionišu prema potrebama zajednice.
Da bi se sve ovo omogućilo neophodno je formirati jasno koncipiranu putanju kroz objekat koja neće praviti nagle promene u prostoru, tako da se korisnik oseća kao da je na trgu (javnom prostoru), koja će u svakom trenutku nuditi drugačiji osećaj i veliku preglednost unutrašnjosti. Jedan od bitnih faktora da bi se svi činioci ovakvog prostora ostvarili jeste i primena svih tehnoloških mogućnosti današnjice.

\section{KONCEPT PROJEKTA TRGOVINSKOG CENTRA NA KLISI}

Najlon pijaca, u naselju Klisa u Novom Sadu, je najnovija novosadska pijaca. Prostire se na $38.000 \mathrm{~m}^{2} \mathrm{sa}$ ukupno 2856 prodajnih mesta, što uključuje i auto pijacu sa 509 mesta. Pijaca radi petkom, subotom i nedeljom. Pijacu vikendom poseti i više od 50.000 ljudi. Iako je Najlon pijaca redovno dosta posećena, a kupci su zadovoljni robom i pristupačnim cenama, prodavci se žale na uslove i skreću pažnju na probleme, krađu i prokišnjavanje.

Projektom su istražene mogućnosti rešavanja navedenih problema kroz izgradnju savremenog trgovinskog centra iznad prostora pijace, koji bi rešio pitanja nedostajućih funkcija postojeće pijace, dodatnih trgovinskih sadržaja naselja, natkrivanja i boljih mikroklimatskih uslova.

$\mathrm{Na}$ osnovu istraživanja koje smo sproveli analiziranjem odnosa tradicionalne pijace i savremene tržnice, zaključujemo da je veoma važno uspostaviti ravnotežu između formalnog savremenog i neformalnog tradicionalnog funkcionisanja pijace/tržnice. Ovaj efekat je najbolje postići sintezom ova dva tipa trgovine kroz zajednički prostor koji ih ne remeti, ali ih deli po svojoj koncepciji na dve odvojene celine. Jedan od načina kako postići ovakav efekat jeste postupak nadgradnje pijace, kao odgovor na problem sinteze funkcionisanja.

Najlon pijacu je neophodno natkriti kako bi tradicionalna Najlon pijaca nesmetano funkcionisala i kada su loši vremenski uslovi napolju, a prostor iznad koji je inače nekoristan pretvoriti $\mathrm{u}$ korisni deo (savremeni šoping centar).

Takav pristup bi omogućio funkcionisanje tako velike površine i ostalim danima, ne samo tri dana u sedmici, što je trenutno slučaj. Uređenjem prostor tržnice bi koristio i kao mesto socijalizacije stanovnika Klise, a takođe i doneo bi efekat decentralizacije Novog Sada.

Takav model pijace treba da omogući samoodrživost objekata (pijaca) i da donese veću ekonomsku dobit gradu, trgovcu, a zajednici veću svest o važnosti socijalizacije i očuvanju vrednosnih karakteristika tradicionalne pijace, koje sve više izumiru i nestaju, zato što ih savremene tržnice u potpunosti gase zbog svoje konkurentnosti i multifunkcionalnosti, i sadržajnosti koje nude kupcu - posetiocu.

Projektom je osmišljen prostor koji uspešno kombinuje dva ista sadržaja pijacu neformalnog oblika i savremeni oblik trgovanja šoping centar, koji je uređenog i sa jasno formiranim komunikacijama i organizacijom prostora. 


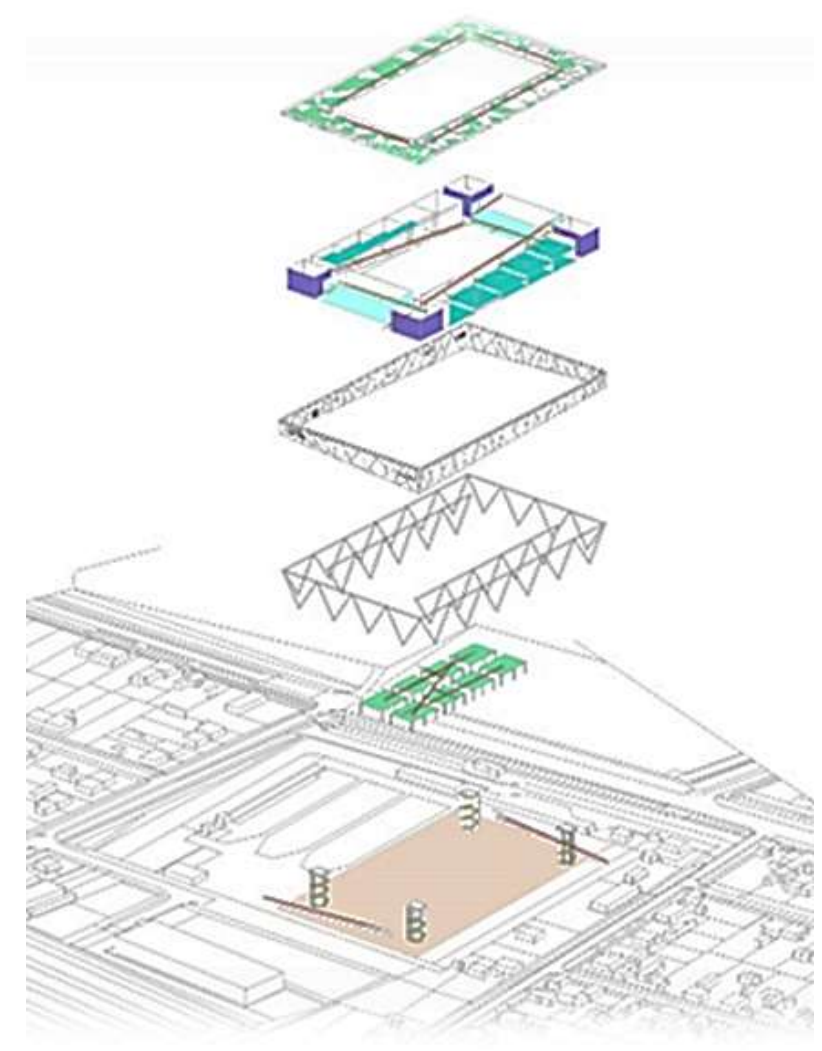

Slika 1. Koncept projekta - aksonometrija

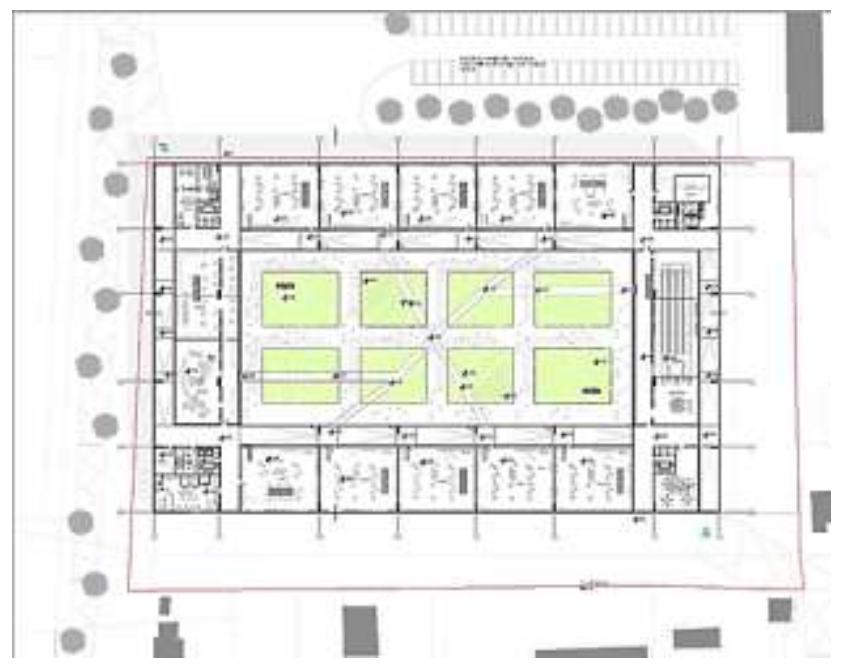

Slika 2. Karakteristična osnova

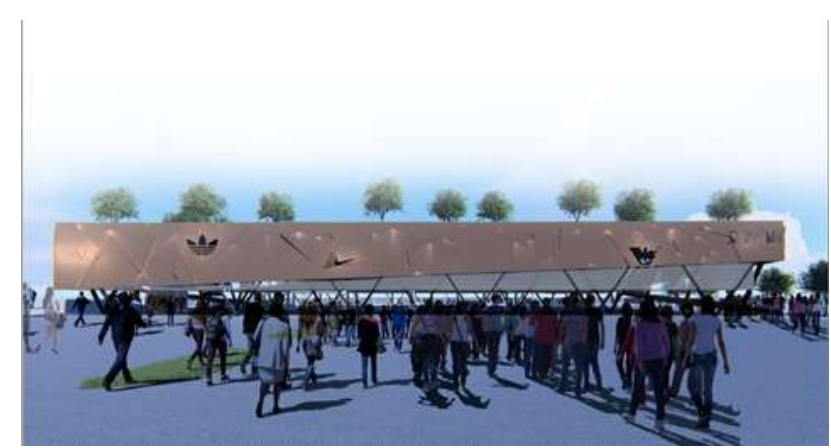

Slika 3. Vizualizacija

\section{ZAKLJUČAK}

Prinicp kombinovanja namena u arhitekturi ili urbanizmu u savremenom društvu je od izuzeznog značaja i potreban je kao neka vrsta eksperimenta, pomoću koga se generišu novi programi i pravci delovanja. Vizuelni identitet objekta značajan je činilac stvaranja veze arhitekture sa savremenim čovekom, dok savremenom društvu jako bitak aspekt čini energetska efikasnost, kao i pogodnost za različito organiziranje prostora (mixed-use).

Projekat kombinacije dva radikalno različita tipa trgovine je veoma kompleksan, kako u funkcionalnom tako i sadržajnom smislu, zato što je u prostoru savremenih tržnica važno odgovoriti na sve zakonske aspekte koji će omogućiti bezbedan i ugodan boravak, kao i pristupačnost svih ljudi. Korišćenjem adekvatne materijalizacije, forme i sistema osvetljenja, prostor dobija nove kvalitete protok i širinu, a osećaj visine nudi otvorenost i zadržava posetioca, i učestvuje u izgradnji vizuelnog identiteta objekta.

Projekat savremene tržnice na Najlon pijaci predstavlja mogući pristup i postupak pri rešavanju problema koje Najlon pijaca i naselje Klisa trenutno poseduje. Ovim se rešava dugogodišnji problem zaštite od vanjskih uticaja i omogućavaju se novi sadržaji za socijalizaciju i relaksiranje.

\section{LITERATURA}

[1] Coleman Peter, Shopping Environments-Evolution, Planning and Design, Oxford: Architectural Press, 2006.

[2] Pravilnik o tehničkim standardima pristupačnosti „Službeni glasnik RS", br. 46/2013

[3] Krier, R. (1991.) Gradski prostor u teoriji i praksi, Beograd: Građevinska knjiga

[4] Lefevr, A. (1974.) Urbana revolucija, Beograd: Nolit, str. 27-29.

[5] https://www.planplus.rs/big-shopping-center-novi$\mathrm{sad} / 35380$ (pristupljeno u maju 2018.)

[6] Horvat, S. (2007.) Znakovi postmodernog grada: prilog semiologiji urbanizma, Zagreb: Naklada Jesenski i Turk, str. 139.

[7] Davis, M. (1992.) City of Quartz: Excavating the Future in Las Angeles, New York: Vintage Books, str. 180 .

\section{Kratka biografija:}

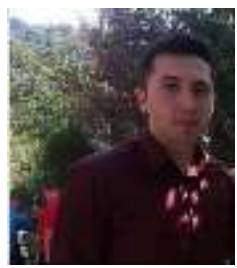

Enes Kurtanović (1993, Novi Pazar) osnovne studije je završio na Državnom univerzitetu u Novom Pazaru 2016. 2017. upisuje master studije na FTN-u smer Arhitektonsko i urbanističko projektovanje, a master rad iz oblasti Arhitektonskog projektovanja odbranio je 2018.god. 